\title{
DIFFERENTIATION BETWEEN BENIGN AND MALIGNANT THYROID NODULE WITH DIFFUSION WEIGHTED MAGNETIC RESONANCE IMAGING AND APPARENT DIFFUSION COEFFICIENT MEASUREMENTS AND ITS HISTOPATHOLOGICAL CORRELATION
}

\author{
Noufal P. M1, K. G. Ramakrishnan², Shailage Kurup ${ }^{3}$, Naseer Ali $^{4}$, Sujith Janardhanan ${ }^{5}$, Tajmal Aboo Rabia ${ }^{6}$, Vipin Unni ${ }^{7}$, Bernaitis L ${ }^{8}$
}

${ }^{1}$ DNB Trainee, Department of Radiology, MIMS Hospital, Calicut.

${ }^{2} H O D$, Department of Radiology, MIMS, Calicut.

${ }^{3}$ Senior Consultant, Department of Radiology, MIMS, Calicut.

${ }^{4}$ Senior Consultant, Department of Endocrinology, MIMS, Calicut.

${ }^{5}$ Consultant, Department of Radiology, MIMS, Calicut.

${ }^{6}$ Consultant, Department of Radiology, MIMS, Calicut.

${ }^{7}$ Lecturer, RVS Dental College, Coimbatore.

${ }^{8}$ Lecturer, Department of Microbiology, RVS Dental College, Coimbatore.

\section{BACKGROUND}

ABSTRACT

The aetiology of thyroid nodules is diverse. Benign causes include the colloid nodule and the classical multinodular goiter. Occasionally, Hashimoto's thyroiditis and Grave's disease may present with nodularity. Malignant causes include thyroid cancer, lymphoma as well as metastasis to the thyroid glands.

The objectives of the study were to compare ADC value of indeterminate thyroid nodules (includes TIRADS 3, 4 \& 5) with their histopathology and then evaluate its role in differentiating malignant from benign thyroid nodules.

\section{MATERIALS AND METHODS}

The prospective study was conducted in Department of Radiology and Imaging Sciences, Malabar Institute of Medical Sciences Ltd, Calicut, Kerala between $1^{\text {st }}$ October 2015 to 30th March 2017, for a period of 18 months. The study population for analysis is the patients undergoing ultrasound thyroid, detected to have TIRADS 3, 4 and 5 lesions. All patients presenting with indeterminate thyroid nodule on ultrasonography in our hospital are subjected to MRI DW sequences the ADC was calculated.

\section{RESULTS}

A total of 80 patients with USG diagnosis of indeterminate thyroid nodule (TIRADS 3, 4 \& 5) that came to the department before undergoing surgery were included in the study. For all these patients, T2 weighted MRI, diffusion weighted imaging and ADC mapping was done. Histopathology findings of each patient is collected and correlated with MRI findings to finalize the diagnosis. The sensitivity and specificity for various ADC values were calculated from ROC curve and it was noted the best ADC value for differentiating benign from malignant thyroid nodules according to our study is 1.745 with the highest sensitivity and specificity to qualify it as a screening test. The positive predictive value and negative predictive value when taking 1.745 as cut off ADC are

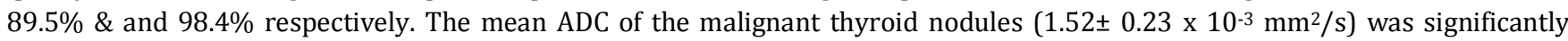
lower than that of the mean ADC of the benign thyroid nodules $\left(2.25 \pm 0.41 \times 10^{-3} \mathrm{~mm}^{2} / \mathrm{s}\right)$. Range of mean ADC value for benign lesions was $1.56-3.33$ and for malignant lesions was $0.96-1.87$. The proportion of cases with malignancy increases with decreasing ADC value. 17 out of 18 malignant cases were having an ADC value of less than 1.745 (Sensitivity - 94.4\%).

\section{CONCLUSION}

The study showed MRI with diffusion weighted imaging and ADC mapping is a promising tool in the armamentarium for the differentiation of benign and malignant thyroid nodules.

\section{KEYWORDS}

Thyroid Nodule, Malignant, Goiter, Radio Imaging, Histopathology, Thyroiditis.

HOW TO CITE THIS ARTICLE: Noufal PM, Ramakrishnan KG, Kurup S, et al. Differentiation between benign and malignant thyroid nodule with diffusion weighted magnetic resonance imaging and apparent diffusion coefficient measurements and its histopathological correlation. J. Evolution Med. Dent. Sci. 2018;7(07):843-849, DOI: 10.14260/jemds/2018/192

\section{BACKGROUND}

Thyroid nodules are the most common disorder of thyroid gland. Thyroid nodules are reported to be found in $33 \%$ of unselected adults between the age of 18 and 65 years and in

'Financial or Other Competing Interest': None.

Submission 14-12-2017, Peer Review 27-01-2018,

Acceptance 02-02-2018, Published 12-02-2018.

Corresponding Author:

Dr. Bernaitis L,

Lecturer,

RUS Dental College, Coimbatore.

E-mail: bernaits_87@yahoo.co.in

DOI: $10.14260 /$ jemds $/ 2018 / 192$

(c) (i) $\$$
$50 \%$ of the population over 65 years of age.(1) Thyroid nodules are found in $4 \%-8 \%$ of adults by palpation, $41 \%$ by sonography, and $50 \%$ by pathologic post-mortem examination.(2) Although in the general population, most thyroid nodules are benign, the prevalence of thyroid cancer is as high as $5 \%-10 \%$.(3)The prevalence of thyroid nodules may vary with age, gender, and population studied. Thyroid nodules are frequently seen in adults and women.

Because of the suspicion of malignancy, thyroid nodules require a detailed examination and Investigation. Clinical examination, ultrasonography (US), radionuclide scintigraphy, and fine-needle aspiration cytology (FNAC) are the common methods to evaluate thyroidal nodularity. The 
prevalence of non-palpable nodules detected by ultrasonography is $30 \%$ in patients younger than 50 years of age and $50 \%$ in patients older than 60 years of age.(4) Many studies have been published to predict whether a thyroid nodule is benign or malignant on the basis of US findings. Several US features have been found to be associated with an increased risk of thyroid cancer including the presence of calcifications, hypo echogenicity, irregular margins, absence of a halo, predominantly solid composition, and intranodular vascularity. However Ultrasound sensitivity and specificity in characterising thyroid nodules vary considerably from study to study and a range between 52 and $97 \%$ and 26.6 and $83 \%$ respectively.(5) No US feature has both high sensitivity and high positive predictive values for thyroid cancer (6).According to American Thyroid Association guidelines, no single US feature or combination of features is adequately sensitive or specific for identification of all malignant nodules (7).US with fine-needle aspiration biopsy (FNAB, cytology) is considered an effective method for differentiating between benign and malignant thyroid nodules and almost exclusively used for de novo diagnosis. In practice, most of these indeterminate nodules undergo FNAC which is an invasive procedure. However, all does not need FNAC since the malignant potential varies from $5 \%-80 \%$. FNAC has inherent limitations with specificity of $60-98 \%$ and a sensitivity of 54$90 \%$ in various studies due to indeterminate and nondiagnostic results.(8) As a result, a significant number of patients eventually receive unnecessary thyroid surgery.

Despite great improvement in diagnostic techniques there is still a large problem to use a non-invasive and reliable technique to differentiate benign from malignant thyroid nodules.(9) To date, little information is available about the use of MR imaging in the diagnosis of thyroid cancer.

Conventional MR imaging cannot differentiate benign from malignant thyroid nodules or assess the functional status of the thyroid nodule.(10) In order to decrease the risk of unnecessary surgery, as well as financial burden to the community, there is a need for a new non-invasive presurgical diagnostic test.(11) Rapid improvements in MRI techniques have resulted in MR images with excellent spatial resolution and soft tissue contrast, which contribute to the differentiation of suspected tumours. Diffusion-weighted MR imaging (DWI) is a noninvasive technique with no radiation exposure, which has the potential to differentiate benign from malignant tissues.(12) During the last 2 decades, DWI has evolved as a helpful diagnostic tool for assessing in vivo tumor characterization, not only in neural lesions but also in extraneural tissue, such as bone marrow pathologies, lymph nodes, and liver tumours. Diffusion weighted imaging (DWI) provides insight into biological and histological characteristics of tissues and may distinguish brain tumor grades, between malignant and benign tumours presumably mainly due to differences in tumor cellularity and biochemical properties of extra-cellular space. Structural changes characteristic of malignancies or benign tissue may result in different signals on DWI, which may be quantified by calculating the apparent diffusion coefficient (ADC). The ADC is an objective parameter that reflects the tissue-specific diffusion capacity and is already being used for tissue characterization and follow-up measurements in therapeutic monitoring.(13) The present study is conducted to compare ADC value of indeterminate thyroid nodules (includes
TIRADS 3, 4 \& 5) with their histopathology and then evaluate its role in differentiating malignant from benign thyroid nodules.

\section{MATERIALS AND METHODS \\ Study Area}

The prospective, observational research study was conducted in the department of radiology and imaging sciences, Malabar institute of medical sciences ltd, Calicut, Kerala. The study was conducted after taking approval from the ethics committee of MIMS hospital.

\section{Study Population}

The study population for analysis is the patients undergoing Ultrasound thyroid detected to have TIRADS 3, 4 and 5 lesions. All participants gave written consent for the study either by themselves or by their close relatives, if they were unable to provide consent. Study samples are selected based on clearly defined criteria as given below.

All patients included presenting with indeterminate thyroid nodule (TIRADS 3, 4 \& 5) in ultrasound in Department of Radiology and Imaging sciences, Malabar Institute of Medical Sciences Calicut during the study period $1^{\text {st }}$ October 2015 to 30 $0^{\text {th }}$ March 2017, for a period of 18 months. Patients Excluded from the study were Normal thyroid, TIRADS 1 and 2, Patients not giving consent, those lost to follow up, Contraindications to MRI studies, such as patients with pacemakers, metallic implants, aneurysmal clips, Claustrophobia.

\section{Imaging Technique and Evaluation Process}

All patients presenting with indeterminate thyroid nodule on ultrasonography in our hospital are subjected to MRI DW sequences according to our department protocol.

MRI studies are done using 1.5 TESLA whole-body system (OPTIMA $450 \mathrm{~W}$ ) with same protocol for all patients.

All patients are asked to get rid of any metallic subjects as well as they are asked about any contraindication to MRI examination (artificial heart valve, cardiac pacemaker, metallic stents or joint prosthesis except that made of titanium. The patients are informed about the duration of the examination, the position of the patient and the importance of being motionless). Patients were in supine position and were instructed not to swallow or move during the examination. Circularly polarized surface coil was placed over the neck. The imaging protocol includes axial $\mathrm{T} 2 * \mathrm{WI}$ (3446/130/90/3) sequences and Diffusion weighted imaging sequences.

\section{Diffusion Weighted MR Imaging (DWI)}

The imaging sequence for DWI is a multi-section, fat suppression spin-echo-type multi-shot echo-planar imaging (EPI) in the axial sequence. Sensitizing diffusion gradients are applied sequentially in the phase encoding direction with $b$ values of 0 and $500 \mathrm{~s} / \mathrm{mm}^{2}$. Sequential sampling of the $\mathrm{K}$ space is used with TR/TE, 2500/95 ms; acquisition matrix 120.120 thickness $5 \mathrm{~mm}$, interslice gap $1 \mathrm{~mm}$, FOV26. $26 \mathrm{~cm}$. ADC was calculated by the following formula: ADC = (lnSI1/SI2)/ (b2-b1), where SI1 and SI2 are signal intensities of sequences S1 and S2 respectively and b1 and b2 are motion probing gradient factors (diffusion factors) of sequences S1 and S2 respectively. 
The ADC value is calculated automatically by a standard MRI software imager and included in the sequence. In order to measure the ADC of the lesions, a circular region of interest (ROI) ranging from 10 to $30 \mathrm{~mm}^{2}$ according to the size of the nodule, and were placed in the center of the lesion in cases of solid nodules and on the solid portion of the lesion in cases of mixed solid-cystic thyroid nodules. ADC value was obtained with $\mathrm{b}$ values 0 and $500 \mathrm{~s} / \mathrm{mm}^{2}$. The ADC values are expressed in square millimetres per second $\left(\mathrm{mm}^{2} / \mathrm{s}\right)$.

\section{Statistical Method \\ Histopathology findings of each patient is collected and correlated with DW and ADC values to finalize the diagnosis. Data will be analysed using SPSS 17.0 (statistical package for social science). Continuous data measurement will be represented as mean with SD or median with inter quantile range according to the distribution of the data. Categorical data will be expressed in frequencies with percentage. Association between categorical variable will be test using Chi Square test or Fishers exact test. Continuous data between two groups will be compared using independent sample t-test or Mann Whitney test. Sensitivity, specificity, accuracy, positive predictive value, negative predictive value will be evaluated in comparison. Ideal cut of will be obtained by Receiver Operator Characteristic Curve (ROC). For all tests a $\mathrm{p}$ value less than 0.05 will be considered as a statistically significant difference. Microsoft word and excel have been used to generate tables and graphs.}

\section{RESULTS}

Over a period of 18 months, a total of 80 patients with USG diagnosis of indeterminate thyroid nodule (TIRADS 3, 4 \&5) that came to the department before undergoing surgery were included in the study after explaining about the study and getting informed consent. Those thyroid nodules those were smaller than $5 \mathrm{~mm}$ was excluded from the study. For all these patients, T2 weighted MRI, diffusion weighted imaging and ADC mapping was done. Histopathology findings of each patient is collected and correlated with MRI findings to finalize the diagnosis.

\section{Demographic Profile of the Patients} Gender distribution of thyroid nodules

Of the 80 patients in the study, $67(83.8 \%)$ were females. This finding is in accordance with the available literature, as thyroid nodules are more common among females, with a male: female ratio of around 1:5 to $1: 2$. In this study the ratio is approximately 1:5.

\section{Percentage of Thyroid Nodules in different Age Groups}

The commonest age group of thyroid nodules was between 41-50 yrs. (28.7\%). The $22.5 \%$ of thyroid nodules are seen in $31-40$ yrs. age group and $21.3 \%$ in $51-60$ age groups. The percentage of nodules in $<20$ years, $21-30$ years, $61-70$ years and $>70$ years are $1.3 \%, 12.5 \%, 113 \%$ and $2.5 \%$ respectively.

\section{Percentage of Malignancy among Age Groups}

The percentage of malignancy is more in the 21-30 years age group and above 70 years age group $50 \%$ of the nodules in the age group) followed by $31-40$ years ( $44.4 \%$ of the nodules in the age group). $22.2 \%$ of thyroid nodules are malignant in $61-70$ years age group and less than $10 \%(8.7 \%)$ in $41-50$ years age group. No malignant nodule was detected in less than 20 years and 51-60 years in this study.

\section{Gender difference in Malignant Nodule}

The gender difference among malignant nodules showed significant difference. Around 46\% (6 out of 13) of nodules were malignant in males and 18\% (12 out of 67 ) in case of females. Thyroid nodules were seen malignant in case of males more than two times compared with that of females.

\section{Ultrasound Features in Thyroid Nodules Echogenicity}

On ultrasound majority (52) of the nodules were hyperechoic (65\%). The nodules which were hypoechoic constitute around $16(20 \%)$ and isoechoic nodules around $12(15 \%)$.

\section{Margin}

On ultrasound the majority (43) of nodules were having smooth margins (53.8\%). The nodules which were having ill defined, lobulated margin constitute 8.8\% (7), irregular around $22.5 \%$ (18) and with extra thyroidal extension around $6.3 \%$ (5).

\section{Composition}

On ultrasound the majority (42) of nodules were solid (52.5\%). The nodules which were solid and cystic constitute around $36(45 \%)$ and spongiform nodules around 2 (2.5\%).

\section{Echogenic Foci}

Micro calcifications are detected in 15 out of 80 (18.8\%) and macro calcifications in 21 out of 80 (26.3\%). No calcification is visualised in 39 out of 80 (48.8\%) nodules. Rim calcification and peripheral calcification were noted in 3 (3.8\%) and $2(2.5 \%)$ nodules respectively.

\section{Distribution of TIRADS Categorization}

Categorization of cases into TIRADS is an important process in the study. All patients (80) who underwent the Ultrasound examination were categorized appropriately. Out of 80 patients examined 46 cases (57.5\%) were included in TIRADS III category, 17 patients each in IV and V categories $(21.3 \%$ each). The below table (Table-6) explain the observation based on TIRADS.

\section{Distribution of Cytology / Histopathology}

The distribution of thyroid nodules is shown in Table-7. The most common nodules were colloid nodule, which accounted for around $2 / 3^{\text {rd }}(53.75)$. Out of the 80 patients 18 patients (22.5\%)were diagnosed with malignancy. 16 patients were diagnosed with papillary carcinoma $(20 \%), 1$ patient with follicular neoplasm (1.3\%)and 1 with anaplastic carcinoma $(1.3 \%)$. Follicular adenoma was diagnosed in 6 patients (7.5\%) and thyroiditis among 13 patients $(16.3 \%)$.

\section{Bivariate Analysis of Ultrasound Characteristics of Thyroid Nodules \\ Bivariate on Echogenicity and Histopathology}

Out of 18 malignant cases, 10 nodules were hypoechoic while 5 were isoechoic and 3 were hyperechoic. Majority of the hyperechoic nodules were benign (49 out of 52). P value $<0.001$ (Table- 1). 


\section{Bivariate on Margins and Histopathology}

All the nodules (5/5) with extra thyroidal extension are malignant. 7 out of 18 and 6 out of 7 nodules with irregular and lobulated margins respectively are malignant. All the nodules with smooth and ill-defined margins are benign. $\mathrm{P}$ value $<0.001$ (Table- 2 ).

\section{Bivariate on Composition and Histopathology}

13 out of 42 solid and 5 out of 36 solid and cystic nodules were malignant. All the spongiform nodules were benign. $\mathrm{P}$ value $<0.001$ (Table- 3 ).

\section{Bivariate on Echogenic foci and Histopathology}

14 out of 15 nodules with micro calcification are malignant. 2 out of 3 and 2 out of 39 nodules with rim and no calcification respectively are malignant. None of the nodules with macro and peripheral calcification are malignant. $\mathrm{P}$ value $<0.001$ (Table- 4).

\section{Bivariate on ACR-TIRADS and Histopathology}

Out of 17 TIRADS V (Highly suspicious of malignancy) nodules 16 were malignant one was benign. 2 out of 17 TIRADS IV (Moderately suspicious of malignancy) nodules were malignant. None of the TIRADS III (Mildly suspicious of malignancy) nodules were malignant in our study. $\mathrm{P}$ value $<0.001$ (Table- 5).

\section{Area under the Curve}

Receiver Operating Curve (ROC) (Fig. 1) for ADC value for differentiating benign from malignancy has a very good area under the curve value of 0.980 . Also, from the ROC curve, the sensitivity and specificity for various ADC value were calculated and the result is as follows (Table -6). It was noted that for the ADC values from 1.655-1.745, the specificity was remaining relatively constant with sensitivity showing an increase from $72.2 \%$ to $94.4 \%$ and with 1.745 as the cut off value of ADC, sensitivity, specificity and accuracy of the study was $94.4 \%, 96.8 \%$ and 96.25 respectively.

\section{Sensitivity and Specificity for different ADC Values}

The best ADC values for differentiating benign from malignant thyroid nodules is 1.745 . With 1.745 as the cut off value of ADC, sensitivity, specificity and accuracy of the study was $94.4 \%, 96.8 \%$ and $96.25 \%$ respectively. The positive predictive value and negative predictive value when taking 1.745 as cut off of ADC are $89.5 \%$ \& and $98.4 \%$ respectively. This value as a cut-off in differentiation of malignant from benign nodules shows a good sensitivity and acceptable specificity.

The proportion of cases with malignancy increases with decreasing ADC value. 17 out of 18 malignant cases were having an ADC value of less than 1.745 (Sensitivity - 94.4\%). Two false positive cases were detected in our study (3.2\%), i.e. 2 out of 62 benign cases have values less than 1.745 .60 out of 62 benign cases were having a value more than 1.745 (Specificity - 96.8\%). One false negative case also detected in our study (5.6\%).

\begin{tabular}{|c|c|c|c|c|c|}
\hline \multicolumn{6}{|c|}{ Crosstab } \\
\hline & & & \multicolumn{2}{|c|}{ Benign/Malignant } & \multirow{2}{*}{ Total } \\
\hline & & & Benign & Malignant & \\
\hline \multirow{6}{*}{ 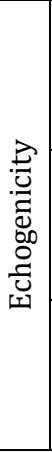 } & \multirow[b]{2}{*}{ Hyperechoic } & Count & 49 & 3 & 52 \\
\hline & & $\begin{array}{l}\% \text { within } \\
\text { Benign/ } \\
\text { Malignant }\end{array}$ & $79.0 \%$ & $16.7 \%$ & $65.0 \%$ \\
\hline & \multirow[b]{2}{*}{ Hypoechoic } & Count & 6 & 10 & 16 \\
\hline & & $\begin{array}{l}\% \text { within } \\
\text { Benign/ } \\
\text { Malignant }\end{array}$ & $9.7 \%$ & $55.6 \%$ & $20.0 \%$ \\
\hline & \multirow[b]{2}{*}{ Isoechoic } & Count & 7 & 5 & 12 \\
\hline & & $\begin{array}{l}\% \text { within } \\
\text { Benign/ } \\
\text { Malignant }\end{array}$ & $11.3 \%$ & $27.8 \%$ & $15.0 \%$ \\
\hline & \multirow[b]{2}{*}{ Total } & Count & 62 & 18 & 80 \\
\hline & & $\begin{array}{l}\text { \% within } \\
\text { Benign/ } \\
\text { Malignant }\end{array}$ & $100.0 \%$ & $100.0 \%$ & $100.0 \%$ \\
\hline \multicolumn{6}{|c|}{$\begin{array}{c}\text { Table 1. Bivariate table on Echogenicity and } \\
\text { Histopathology }\end{array}$} \\
\hline
\end{tabular}

\begin{tabular}{|c|c|c|c|c|c|}
\hline & \multicolumn{2}{|c|}{ Benign/malignant } & \multirow{2}{*}{ Total } \\
\hline & & & Benign & Malignant & \\
\hline \multirow{10}{*}{ 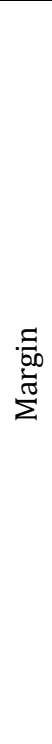 } & \multirow[b]{2}{*}{$\begin{array}{c}\text { Extra- } \\
\text { thyroidal } \\
\text { extension }\end{array}$} & Count & 0 & 5 & 5 \\
\hline & & $\begin{array}{l}\text { \% within } \\
\text { Benign/ } \\
\text { Malignant }\end{array}$ & $0.0 \%$ & $27.8 \%$ & $6.2 \%$ \\
\hline & \multirow[b]{2}{*}{ Ill-defined } & Count & 7 & 0 & 7 \\
\hline & & \% within & $11.3 \%$ & $0.0 \%$ & $8.8 \%$ \\
\hline & \multirow[b]{2}{*}{ Irregular } & Count & 11 & 7 & 18 \\
\hline & & $\begin{array}{l}\text { \% within } \\
\text { Benign/ }\end{array}$ & $17.7 \%$ & $38.9 \%$ & $22.5 \%$ \\
\hline & \multirow[b]{2}{*}{ Lobulated } & Count & 1 & 6 & 7 \\
\hline & & $\begin{array}{l}\text { \% within } \\
\text { Benign } \\
\text { /Malignant }\end{array}$ & $1.6 \%$ & $33.3 \%$ & $8.8 \%$ \\
\hline & \multirow[b]{2}{*}{ Smooth } & Count & 43 & 0 & 43 \\
\hline & & $\begin{array}{l}\text { \% within } \\
\text { Benign/ } \\
\text { Malignant }\end{array}$ & $69.4 \%$ & $0.0 \%$ & $53.8 \%$ \\
\hline & \multirow[b]{2}{*}{ Total } & Count & 62 & 18 & 80 \\
\hline & & $\begin{array}{l}\text { \% within } \\
\text { Benign/ } \\
\text { Malignant }\end{array}$ & $100.0 \%$ & $100.0 \%$ & $100.0 \%$ \\
\hline
\end{tabular}

\begin{tabular}{|c|c|c|c|c|c|}
\hline \multicolumn{6}{|c|}{ Crosstab } \\
\hline & & & \multicolumn{2}{|c|}{ Benign/Malignant } & \multirow{2}{*}{ Total } \\
\hline & & & Benign & Malignant & \\
\hline \multirow{6}{*}{ 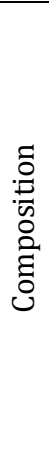 } & & Count & 29 & 13 & 42 \\
\hline & Solid & $\begin{array}{l}\% \text { within } \\
\text { Benign/ } \\
\text { Malignant }\end{array}$ & $46.8 \%$ & $72.2 \%$ & $52.5 \%$ \\
\hline & \multirow[b]{2}{*}{$\begin{array}{l}\text { Solid and } \\
\text { cystic }\end{array}$} & Count & 31 & 5 & 36 \\
\hline & & $\begin{array}{l}\text { \% within } \\
\text { Benign/ } \\
\text { Malignant }\end{array}$ & $50.0 \%$ & $27.8 \%$ & $45.0 \%$ \\
\hline & \multirow[b]{2}{*}{ Spongiform } & Count & 2 & 0 & 2 \\
\hline & & $\begin{array}{l}\text { \% within } \\
\text { Benign/ } \\
\text { Malignant }\end{array}$ & $3.2 \%$ & $0.0 \%$ & $2.5 \%$ \\
\hline
\end{tabular}




\begin{tabular}{|c|c|c|c|c|}
\hline \multirow{3}{*}{ Total } & Count & 62 & 18 & 80 \\
\cline { 2 - 5 } & $\begin{array}{c}\text { \% within } \\
\text { Benign/ } \\
\text { Malignant }\end{array}$ & $100.0 \%$ & $100.0 \%$ & $100.0 \%$ \\
\hline Table 3. Bivariate table on Composition and \\
Histopathology \\
\hline
\end{tabular}

\begin{tabular}{|c|c|c|c|c|c|}
\hline \multicolumn{6}{|c|}{ Crosstab } \\
\hline & & & \multicolumn{2}{|c|}{ Benign/Malignant } & \multirow{3}{*}{$\begin{array}{l}\text { Total } \\
39\end{array}$} \\
\hline & & & Benign & Malignant & \\
\hline \multirow{10}{*}{ 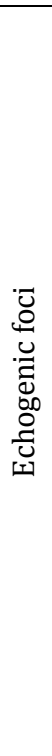 } & \multirow[b]{2}{*}{ Nil } & Count & 37 & 2 & \\
\hline & & $\begin{array}{c}\text { \% within } \\
\text { Benign/ } \\
\text { Malignant }\end{array}$ & $59.7 \%$ & $11.1 \%$ & $48.8 \%$ \\
\hline & \multirow[b]{2}{*}{$\begin{array}{l}\text { Macro } \\
\text { calcification }\end{array}$} & Count & 21 & 0 & 21 \\
\hline & & $\begin{array}{c}\% \text { within } \\
\text { Benign/ } \\
\text { Malignant }\end{array}$ & $33.9 \%$ & $0.0 \%$ & $26.2 \%$ \\
\hline & \multirow[b]{2}{*}{$\begin{array}{l}\text { Micro } \\
\text { calcification }\end{array}$} & Count & 1 & 14 & 15 \\
\hline & & $\begin{array}{c}\% \text { within } \\
\text { Benign/ } \\
\text { Malignant }\end{array}$ & $1.6 \%$ & $77.8 \%$ & $18.8 \%$ \\
\hline & \multirow[b]{2}{*}{$\begin{array}{l}\text { Peripheral } \\
\text { calcification }\end{array}$} & Count & 2 & 0 & 2 \\
\hline & & $\begin{array}{c}\% \text { within } \\
\text { Benign/ } \\
\text { Malignant }\end{array}$ & $3.2 \%$ & $0.0 \%$ & $2.5 \%$ \\
\hline & \multirow[b]{2}{*}{$\underset{\text { calcification }}{\operatorname{Rim}}$} & Count & 1 & 2 & 3 \\
\hline & & $\begin{array}{c}\% \text { within } \\
\text { Benign/ } \\
\text { Malignant }\end{array}$ & $1.6 \%$ & $11.1 \%$ & $3.8 \%$ \\
\hline & \multirow[b]{2}{*}{ Total } & Count & 62 & 18 & 80 \\
\hline & & $\begin{array}{c}\% \text { within } \\
\text { Benign/ } \\
\text { Malignant }\end{array}$ & $100.0 \%$ & $100.0 \%$ & $100.0 \%$ \\
\hline \multicolumn{6}{|c|}{$\begin{array}{c}\text { Table 4. Bivariate table on Echogenic foci and } \\
\text { Histopathology }\end{array}$} \\
\hline
\end{tabular}

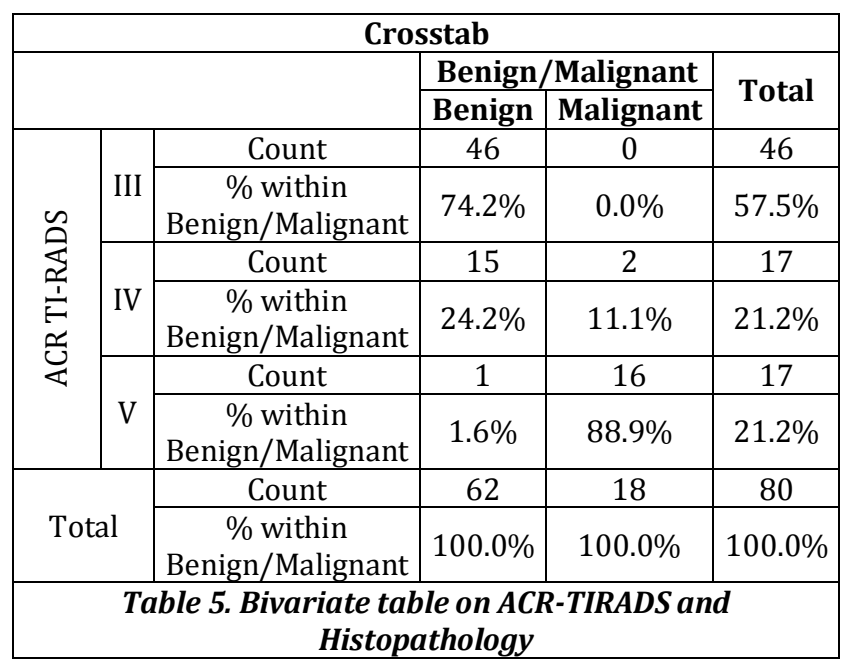

\begin{tabular}{|c|c|c|c|c|}
\hline \multicolumn{5}{|c|}{ Area Under the Curve } \\
\hline \multicolumn{5}{|c|}{ Test Result Variable(s): ADC VALUE (B 500) } \\
\hline \multirow{2}{*}{ Area } & \multirow{2}{*}{$\begin{array}{l}\text { Std. } \\
\text { Errora }\end{array}$} & \multirow{2}{*}{ P VALUE } & \multicolumn{2}{|c|}{$\begin{array}{c}\text { Asymptotic } 95 \% \\
\text { Confidence Interval }\end{array}$} \\
\hline & & & $\begin{array}{l}\text { Lower } \\
\text { Bound }\end{array}$ & $\begin{array}{l}\text { Upper } \\
\text { Bound }\end{array}$ \\
\hline .980 & .013 & $<0.001$ & .954 & 1.000 \\
\hline
\end{tabular}

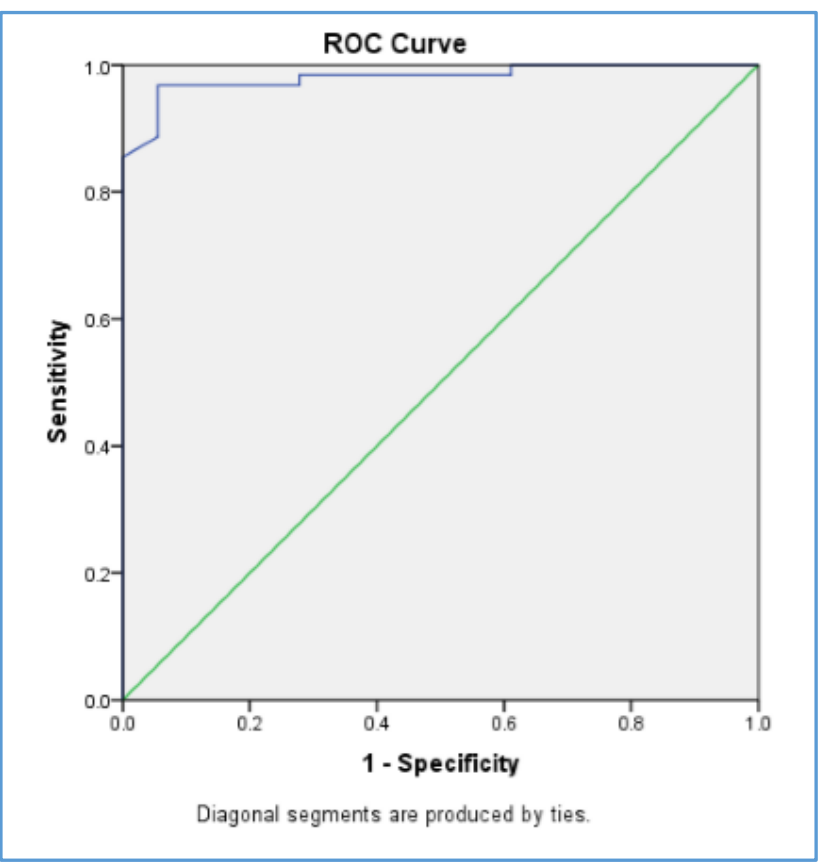

Figure 1. ROC Curve

\section{DISCUSSION}

The improved detection of thyroid nodules with Ultrasound has resulted in an increase in the number of thyroid FNABs and, thus, an increase in the number of thyroid cancers diagnosed (14). Appropriate criteria are necessary to avoid an increase of rather unnecessary benign cytological results and surgery in thyroid nodules. Thyroid Imaging Reporting and Data System (TIRADS) has been developed based on the concepts of Breast Imaging Reporting and Data System (BIRADS), which established different categories according to the percentage of malignancy. Since its publication by Hovarth in JCEM9,(15) its clinical use is still very limited and its practicability in clinical practice is questioned. The Ultrasound patterns described were not applicable to all thyroid nodules and this stereotypic Ultrasound application is difficult for Ultrasound performers to use. All TIRADS 3 and 4 nodules does not need FNAC since the malignant potential varies from $2 \%$ - 85\%.(16) Alternative imaging techniques like Diffusion MRI can be used to improve the diagnostic accuracy.

This is a prospective study to analyse the diagnostic benefit of diffusion-weighted magnetic resonance imaging (DWI) in the differentiation of malignant from benign thyroid nodules and to avoid unnecessary biopsies.

In our study, a total of 80 patients with age range 19 to 79 year were included. The commonest age group of thyroid nodules was between $41-50$ yrs. (28.7\%). The $22.5 \%$ of thyroid nodules are seen in 31-40 yrs. age group and $21.3 \%$ in 51-60 age groups. The percentage of nodules in $<20$ years, 21-30 years, $61-70$ years and $>70$ years are $1.3 \%, 12.5 \%$, $113 \%$ and $2.5 \%$ respectively. The percentage of malignancy is more in 21-30 years. age group and above 70 years age group ( $50 \%$ of the nodules in the age group). The cohort of population we studied contained more of younger age group. So that may be reason why we picked up more malignant lesions in younger age groups.

Majority of the patients were females (83.8\%) in our study with a male to female ratio of $1: 5$ that correspond to that in reported literature (17). Also, more number of 
malignant thyroid nodules were found in males (46\%) compared to females (18\%).

Histopathologically, the most common nodules were colloid nodule, which accounted for around $2 / 3^{\text {rd }}$ (53.75). Out of the 80 patients 18 patients (22.5\%)were diagnosed with malignancy. 16 patients were diagnosed with papillary carcinoma (20\%), 1 patient with follicular neoplasm (1.3\%)and 1 with anaplastic carcinoma (1.3\%). Follicular adenoma were diagnosed in 6 patients $(7.5 \%)$ and thyroiditis among 13 patients (16.3\%).

Out of 18 malignant cases, 10 nodules were hypoechoic while 5 were isoechoic and 3 were hyperechoic. Majority of the hyperechoic nodules were benign ( 49 out of 52 ).

All the nodules (5/5) with extrathyroidal extension are malignant. 7 out of 18 and 6 out of 7 nodules with irregular and lobulated margins respectively are malignant. All the nodules with smooth and ill-defined margins are benign.

13 out of 42 solid and 5 out of 36 solid and cystic nodules were malignant. All the spongiform nodules were benign.

14 out of 15 nodules with microcalcification were malignant. 2 out of 3 and 2 out of 39 nodules with rim and no calcification respectively are malignant. None of the nodules with macro and peripheral calcification are malignant.

Out of 17 TIRADS $\mathrm{V}$ (Highly suspicious of malignancy) nodules 16 were malignant one was benign. 2 out of 17 TIRADS IV (Moderately suspicious of malignancy) nodules were malignant. None of the TIRADS III (Mildly suspicious of malignancy) nodules were malignant in our study.

The sensitivity and specificity for various ADC values were calculated from ROC curve and it was noted that for the ADC values from 1.655-1.745, the specificity was remaining relatively constant with sensitivity showing an increase from $72.2 \%$ to $94.4 \%$ and with 1.745 as the cut off value of ADC, sensitivity, specificity and accuracy of the study was $94.4 \%$, $96.8 \%$ and 96.25 respectively. The best ADC value for differentiating benign from malignant thyroid nodules according to our study is 1.745 with the highest sensitivity and specificity to qualify it as a screening test. The positive predictive value and negative predictive value when taking 1.745 as cut off ADC are $89.5 \%$ \& and $98.4 \%$ respectively. The mean ADC of the malignant thyroid nodules $\left(1.52 \pm 0.23 \times 10^{-3}\right.$ $\mathrm{mm}^{2} / \mathrm{s}$ ) was significantly lower than that of the mean ADC of the benign thyroid nodules $\left(2.25 \pm 0.41 \times 10^{-3} \mathrm{~mm}^{2} / \mathrm{s}\right)$. Range of mean ADC value for benign lesions was $1.56-3.33$ and for malignant lesions was $0.96-1.87$.

The proportion of cases with malignancy increases with decreasing ADC value. 17 out of 18 malignant cases were having an ADC value of less than 1.745 (Sensitivity - 94.4\%). Two false positive cases were detected in our study (3.2\%), 1) Follicular adenoma (ADC-1.56 X 10-3) 2) Nodular colloid goiter (ADC-1.65 X 10-3). The false positivity may be due to high cellularity of the lesion. 60 out of 62 benign cases were having a value more than 1.745 (Specificity - 96.8\%). One false negative case was detected in our study (Papillary carcinoma - ADC- $1.87 \times 10^{-3}$ ) and on histopathology necrosis with haemorrhage was detected within the lesion. The results are in par with the meta-analysis done by Chen L.(18)

The result is comparable with Shi HF et al (19) who did a comparative study of Utility of diffusion-weighted imaging in differentiating malignant from benign thyroid nodules with magnetic resonance imaging and pathologic correlation. The majority (65\%) of malignant thyroid nodules showed slightly hyperintense, and the majority (69\%) of benign nodules were hyperintense on DWI $(\mathrm{P}<0.01)$. The ADC values were lower in the thyroid cancer than in the adenoma and nodular goiter $(\mathrm{P}<0.05)$. When the $\mathrm{b}$ factor was $500 \mathrm{~s} / \mathrm{mm}$, an ADC value of $1.704 \times 10 \mathrm{~mm} / \mathrm{s}$ can be threshold differentiating malignant from benign nodules, with $92 \%$ sensitivity, $88 \%$ specificity, and $87 \%$ accuracy. The higher cell density and more severe desmoplastic response were the causes of the lower ADC value of thyroid cancer.

The result is also comparable with Yan et al (20) who did a study to assess the application of ADC value in differentiating benign and malignant thyroid nodules with MR DWI. The ADC values of 40 thyroid nodules from 27 patients confirmed pathologically were analysed retrospectively. Routine MR $\mathrm{T} 1 \mathrm{~W}, \mathrm{~T} 2 \mathrm{~W}$ and contrast enhanced fat suppression scan were performed to confirm the solidity of thyroid nodules. DWI were acquired using single shot spin echo-planner imaging (SS SE-EPI) sequence with diffusion-sensitizing gradients using $\mathrm{b}$ factors of 0 and $500 \mathrm{~s} / \mathrm{mm}^{2}$. Thyroid nodules were divided into malignant and benign groups based on the pathological findings. ADC values of both groups were compared, and ROC curves were drawn to determine the diagnostic threshold and assess the screening test. Fifteen of 40 thyroid nodules were malignant and 25 were benign. The mean ADC value for benign thyroid nodules was $(2.20 \pm 0.40)$ $\times 10-3 \mathrm{~mm}^{2} / \mathrm{s}, 95 \%$ confidence interval was $(2.04-2.37)$ $\times 10-3 \mathrm{~mm}^{2} / \mathrm{s}$. The mean ADC value for thyroid malignancy was $(1.22 \pm 0.27) \times 10-3 \mathrm{~mm}^{2} / \mathrm{s}, 95 \%$ confidence interval was(1.07-1.37) $\times 10-3 \mathrm{~mm}^{2} / \mathrm{s}$ significantly lower than that of benign thyroid nodules ( $P$ 0.05). When the area under the ROC curve was 0.98 , the diagnostic threshold was $1.49 \times 10-3$ $\mathrm{mm}^{2} / \mathrm{s}$ the sensitivity, specificity and accuracy was $86.70 \%$, $100 \%$ and $95.00 \%$, respectively.

In January 2012, study by El-Hariri, et al(21)showed that the mean ADC of the malignant thyroid nodules $(0.89 \pm 0.27 \mathrm{x}$ $10^{-3} \mathrm{~mm}^{2} / \mathrm{s}$ ) was significantly lower than that of the mean ADC of the benign thyroid nodules $\left(1.85 \pm 0.24 \times 10^{-3} \mathrm{~mm}^{2} / \mathrm{s}\right)$. ADC value of $1.5 \times 10^{-3} \mathrm{~mm}^{2} / \mathrm{s}$ was used as a cut-off value for differentiation benign from malignant thyroid nodules. The sensitivity, specificity, PPV \& NPV of DWI in differentiating benign from malignant thyroid nodules were 94\%, 95\%, 94\% \& 95\%, respectively.

All the above studies are in par with our study showing significant difference in ADC value between the malignant tumours and benign lesions with reduced ADC value in malignant lesions compared to benign lesions.

C. Schueller-Weidekamm et al (22) done a study of Quantitative Diffusion-Weighted MR Imaging to Differentiate Benign and Malignant Cold Thyroid Nodules. Histologically, there were 20 carcinomas with a minimum size of $8 \mathrm{~mm}$ and 5 adenomas. The mean ADC values (in $10^{-3} \mathrm{~mm}^{2} / \mathrm{s}$ ) differed significantly among carcinoma, adenoma, and normal parenchyma $(\mathrm{P}<.05)$. The ranges $(95 \%$ confidence interval) of the ADC values for carcinoma (2.43-3.037), adenoma (1.6262.233), and normal parenchyma (1.253-1.602) showed no overlap. When an ADC value of 2.25 or higher was used for predicting malignancy, the highest accuracy of $88 \%$, with $85 \%$ sensitivity and $100 \%$ specificity, was obtained. This study was not in accordance with our study.

Hence findings of our study and other studies quoted above suggest that the ADC values can well be used in the differentiation of benign and malignant thyroid nodules. 
Different studies showed difference in the ADC cut off values for predicting thyroid carcinoma which is evident from several different studies quoted above. Hence each MRI unit should determine the exact threshold value for predicting malignancy in thyroid nodules as there are variations in MRI systems, coils and pulse sequences. Zhu and his colleagues,(23) mentioned that at lower b-values, there is risk of perfusion contamination, so the measured ADC will not be reliable to assess diffusion of tissues by mixed effects of perfusion and diffusion that could not be separated at these levels while at high b-values, there is risk of noise contamination and bad images resolution with subsequent non-reliable ADC measurement. They added that at least two b-values should be used to obtain an accurate quantitative analysis of diffusion-weighted images and consequently reliable ADC maps as well as the ADC measurement.

\section{CONCLUSION}

MRI with diffusion weighted imaging and ADC mapping is a promising tool in the armamentarium for the differentiation of benign and malignant thyroid nodules. It is superior to other modalities by using no ionizing radiation, its ability to probe the microstructure, its short acquisition time, its high repeatability, its safety, its affordability and the absence of intravenous administration of contrast

\section{REFERENCES}

[1] Reiners C, Wegscheider K, Schicha H, et al. Prevalence of thyroid disorders in the working population of Germany: ultrasonography screening in 96,278 unselected employees. Thyroid 2004;14(11):926-32.

[2] Brander A, Viikinkoski P, Nickels J, et al. Thyroid gland: US screening in a random adult population. Radiology 1991;181(3):683-7.

[3] Tumbridge WM, Evered DC, Hall R, et al. The spectrum of thyroid disease in a community: the Whickham Survey. Clin Endocrinol (Oxf) 1977;7(6):481-93.

[4] Baloch ZW, Cibas ES, Clark DP, et al. The National Cancer Institute Thyroid Fine-Needle Aspiration State of the Science Conference: a summation. Cytojournal 2008;5:6.

[5] Mazzaferri EL. Thyroid cancer in thyroid nodules: finding a needle in the haystack. Am J Med 1992;93(4):359-62.

[6] Fish SA, Langer JE, Mandel SJ. Sonographic imaging of thyroid nodules and cervical lymph nodes. Endocrinology and Metabolism Clinics of North America 2008;37(2):401-17.

[7] Kim HG, Moon HJ, Kwak JY, et al. Diagnostic accuracy of the ultrasonographic features for subcentimeter thyroid nodules suggested by the revised American Thyroid Association guidelines. Thyroid 2013;23(12):1583-9.

[8] Frates MC, Benson CB, Charboneau JW, et al. Management of thyroid nodules detected at US: Society of Radiologists in Ultrasound consensus conference statement. Radiology 2005;237(3):794800 .
[9] Cooper DS, Doherty GM, Haugen BR, et al. Management guidelines for patients with thyroid nodules and differentiated thyroid cancer: Thyroid 2006;16(2):109-42.

[10] Tee YY, Lowe AJ, Brand CA, et al. Fine-needle aspiration may miss a third of all malignancy in palpable thyroid nodules: a comprehensive literature review. Annals of Surgery 2007;246(5):714-20.

[11] Peng Y, Wang HH. A meta-analysis of comparing fine-needle aspiration and frozen section for evaluating thyroid nodules. Diagnostic Cytopathology 2008;36(12):916-20.

[12] Oertel YC, Miyahara-Felipe L, Mendoza MG, et al. Value of repeated fine needle aspirations of the thyroid: an analysis of over ten thousand FNAs. Thyroid 2007;17(11):1061-6.

[13] Gotway MB, Higgins CB. MR imaging of the thyroid and parathy-roid glands. Magn Reson Imaging Clin N Am 2000;8(1):163-82.

[14] Nakahara H, Noguchi S, Murakami N, et al. Gadoliniumenhanced MR imaging of thyroid and parathyroid masses. Radiology 1997;202(3):765-72.

[15] Horvath E, Majlis S, Rossi R, et al. An ultrasonogram reporting system for thyroid nodules stratifying cancer risk for clinical management. The Journal of Clinical Endocrinology \& Metabolism 2009;94(5):1748-51.

[16] Le Bihan D, Turner R, Douek P, et al. Diffusion MR imaging: clinical applications. AJR Am J Roentgenol 1992;159(3):591-9.

[17] Eis M, Els T, Hoehn-Berlage M. High resolution quantitative relaxation and diffusion MRI of three different experimental brain tumors in rat. Magn Reson Med 1995;34(6):835-44.

[18] Chen L, Xu J, Bao J, et al. Diffusion-weighted MRI in differentiating malignant from benign thyroid nodules: a meta-analysis. BMJ Open 2016;6(1):e008413.

[19] Shi HF, Feng Q, Qiang JW, et al. Utility of diffusionweighted imaging in differentiating malignant from benign thyroid nodules with magnetic resonance imaging and pathologic correlation. Journal of Computer Assisted Tomography 2013;37(4):505-10.

[20] Yan B, Liu HJ, Wang CB, et al. ADC values in differentiation of benign and malignant thyroid nodules. Chin J Med Imaging Technol 2011;27:510-4.

[21] El-Hariri MA, Gouhar GK, Said NS, et al. Role of diffusion-weighted imaging with ADC mapping and in vivo $1 \mathrm{H}-\mathrm{MR}$ spectroscopy in thyroid nodules. The Egypt J Radiol Nucl Med 2012;43(2):183-92.

[22] Schueller-Weidekamm C, Kaserer K, Schueller G, et al. Can quantitative diffusion-weighted $\mathrm{MR}$ imaging differentiate benign and malignant cold thyroid nodules? Initial results in 25 patients. AJNR Am J Neuroradiol 2009;30(2):417-22.

[23] Zhu NY, Chen KM, Chai WM, et al. Feasibility of diagnosing and staging liver fibrosis with diffusion weighted imaging. Chin Med Sci J 2008;23(3):183-6. 